\title{
Influence of particle size on the in vitro and in vivo anti-inflammatory and anti-allergic activities of a curcumin lipid nanoemulsion
}

\author{
TAKEFUMI ONODERA ${ }^{1,2}$, ISOKO KURIYAMA ${ }^{2,3}$, TOORU ANDOH ${ }^{2,4}$, HIDEKI ICHIKAWA ${ }^{2,4}$, \\ YUKA SAKAMOTO $^{1}$, EIBAI LEE-HIRAIWA ${ }^{2,3}$ and YOSHIYUKI MIZUSHINA ${ }^{2,5}$
}

\author{
${ }^{1}$ Laboratory of Food and Nutritional Sciences, Faculty of Nutrition, Kobe Gakuin University, Kobe, Hyogo 651-2180; \\ ${ }^{2}$ Cooperative Research Center of Life Sciences, Kobe Gakuin University; ${ }^{3}$ Laboratory of Pharmacology, \\ Faculty of Pharmaceutical Sciences, Kobe Gakuin University; ${ }^{4}$ Laboratory of Pharmaceutical Technology, \\ Faculty of Pharmaceutical Sciences, Kobe Gakuin University, Kobe, Hyogo 651-8586; \\ ${ }^{5}$ Graduate School of Agriculture, Shinshu University, Kamiina-gun, Nagano 399-4598, Japan
}

Received February 5, 2015; Accepted April 9, 2015

DOI: $10.3892 /$ ijmm.2015.2186

\begin{abstract}
The polyphenolic compound, curcumin, is a natural yellow pigment component of turmeric. It exerts various biological effects, such as anti-inflammatory effects, and we have previously demonstrated that curcumin is a specific inhibitor of DNA polymerase $\lambda$. Curcumin is characterized by poor bioavailability as it is water-insoluble, is poorly absorbed and is systemically eliminated. In order to increase the bioavailability of curcumin, in this study, we produced a curcumin-loaded lipid nanoemulsion of various particle sizes $(50,100$ and $200 \mathrm{~nm})$. The curcumin lipid nanoemulsion was prepared by a modified thinfilm hydration method followed by sonication. To identify the optimal particle size which exhibits the strongest physiological activity, we investigated the inhibitory effects of the obtained nanoemulsions against inflammatory and allergic activities. In in vitro cell culture experiments, the $100-\mathrm{nm}$ curcumin lipid nanoemulsion showed the most prominent inhibitory effect on the production of tumor necrosis factor- $\alpha$ (TNF- $\alpha)$ induced by lipopolysaccharide (LPS) in RAW264.7 murine macrophages, and on the release of $\beta$-hexosaminidase induced by the calcium ionophore, A23187, in rat basophilic leukemia RBL-2H3 cells.
\end{abstract}

Correspondence to: Dr Yoshiyuki Mizushina, Graduate School of Agriculture, Shinshu University, 8304 Minamiminowa-mura, Kamiina-gun, Nagano 399-4598, Japan

E-mail:mizushina@shinshu-u.ac.jp

Abbreviations: Pol,DNA polymerase; TNF- $\alpha$, tumor necrosis factor- $\alpha$; LPS, lipopolysaccharide; TPA, 12- $O$-tetradecanoylphorbol-13-acetate; $\mathrm{O} / \mathrm{W}$, oil-in-water; HEPC, hydrogenated L- $\alpha$-phosphatidylcholine; ELISA, enzyme-linked immunosorbent assay; PCA, passive cutaneous anaphylaxis; DNP, anti-dinitrophenyl; IgE, immunoglobulin E; HPLC, high-performance liquid chromatography; SD, standard deviation

Key words: curcumin, lipid nanoemulsion, anti-inflammatory, tumor necrosis factor- $\alpha$, anti-allergic, $\beta$-hexosaminidase
In an in vivo experiment, in which mice were administered the curcumin-loaded lipid nanoemulsion of various particle sizes, the 100-nm curcumin lipid nanoemulsion showed the most prominent anti-inflammatory and anti-allergic effects, inhibiting 12-O-tetradecanoylphorbol-13-acetate-induced inflammatory ear edema and immunoglobulin E ( $\mathrm{IgE}$ )-induced passive cutaneous anaphylactic (PCA) reaction. The effects of particle size on serum curcumin absorption were also assessed in mice, and the 100-nm lipid nanoemulsion showed the greatest absorption. The results from our study suggest that the physiological activities of curcumin lipid nanoemulsions differ depending on particle size. Our data indicate that the curcumin lipid nanoemulsion with a particle size of $100 \mathrm{~nm}$ has potential for use in enhancing the bioavailability and medical value of curcumin.

\section{Introduction}

Curcumin, a hydrophobic polyphenol derived from the rhizome of the herb, Curcuma longa (turmeric), has a wide spectrum of biological and pharmacological activities. Chemically, curcumin is a bis- $\alpha, \beta$-unsaturated $\beta$-diketone (commonly known as diferuloylmethane), which exhibits keto-enol tautomerism having a predominant keto form in acidic and neutral solutions and a stable enol form in alkaline media. Turmeric has traditionally been used in the treatment of a number of ailments, particularly as an anti-inflammatory agent, and curcumin has been identified as the active component (1). Curcumin has been shown to possess anti-inflammatory $(2)$, antibacterial $(3,4)$, antifungal and anti-yeast (5), anti-hypercholesterolemic (6), anticancer (7-10), antimutagenic (11), antiparasitic (12), antitumor-promoting (13), anti-proliferative (14), as well as MDR modulator effects (15), among others. In previous studies of ours, we reported that curcumin specifically inhibited the activity of DNA polymerase $\lambda$ ( $\mathrm{Pol} \lambda$ ), a DNA repair/ recombination Pol, with a half-maximal inhibitory concentration $\left(\mathrm{IC}_{50}\right)$ of $7.0 \mu \mathrm{M}(16,17)$. This compound also suppressed the lipopolysaccharide (LPS)-induced production of tumor 
necrosis factor- $\alpha$ (TNF- $\alpha$ ) in RAW264.7 murine macrophages and attenuated 12-O-tetradecanoylphorbol-13-acetate (TPA)induced ear inflammation in mice $(16,18)$. We have also previousy suggested that the anti-inflammatory effects of curcumin may due to the inhibition of Pol $\lambda$ activity (19).

Several investigators, ourselves included, have investigated plasma curcumin levels in clinical trials and have reported that plasma levels remained low despite the intake of gram doses of curcumin (20-23). Furthermore, a curcumin intake $>8 \mathrm{~g}$ was not shown to increase blood curcumin levels in healthy volunteers (24). Thus, the low bioavailability of curcumin is a major issue facing investigators seeking to verify the therapeutic efficacy of this promising agent in clinical trials. Therefore, we focused on improving the bioavailability of curcumin through the use of an innovative drug delivery system, whereby curcumin is incorporated into a lipid emulsion of various nanoorder diameters (i.e., lipid nanoemulsion).

Emulsion-based delivery systems are being increasingly used in the pharmaceutical industry to incorporate lipophilic bioactive components (25). Nanoemulsions, or oilin-water $(\mathrm{O} / \mathrm{W})$ emulsions, can be prepared by solubilizing lipophilic bioactive components within the oil phase, and then homogenizing this phase with an aqueous phase containing a water-soluble emulsifier. The size of the droplets produced depends on the composition of the system and the homogenization method employed. $\mathrm{O} / \mathrm{W}$ conventional emulsions and nanoemulsions are both thermodynamically unstable systems that consist of emulsifier-coated lipid droplets dispersed within an aqueous medium (26). Lipid emulsions have also been used as a promising drug delivery system to target tissues $(27,28)$. Moreover, a number of studies have demonstrated the validity of lipid emulsions as a parenteral drug delivery device (29-31). They have certain advantages, such as good biocompatibility, biodegradability, physical stability and ease of large-scale production. In addition, they can incorporate hydrophobic and amphipathic drugs due to their structural characteristics. Since curcumin is hydrophobic in nature, it can be incorporated into a lipid emulsion. Thus, lipid emulsions represent a promising means with which to deliver curcumin.

In the present study, we prepared curcumin lipid nanoemulsions of various particle sizes and assessed the effects of particle size the on physiological activities, such as the antiinflammatory and anti-allergoc activities, of curcumin in vitro and in vivo.

\section{Materials and methods}

Materials. Curcumin and LPS were purchased from Sigma-Aldrich, Inc. (St. Louis, MO, USA). Murine macrophages (RAW264.7) and rat basophilic leukemia (RBL-2H3) cells were obtained from the American Type Culture Collection (ATCC, Manassas, VA, USA). All other reagents were of analytical grade and were obtained from Nacalai Tesque, Inc. (Kyoto, Japan).

Preparation of curcumin lipid nanoemulsions. The curcumin lipid nanoemulsions ( $\mathrm{O} / \mathrm{W}$ emulsions) were prepared using a slightly modified thin-film hydration method at room temperature $\left(24^{\circ} \mathrm{C}\right)$ as previously described $(32,33)$. In brief, the emulsions consisted of soybean oil, hydrogenated L- $\alpha$-phosphatidylcholine (HEPC) from egg yolk, water, curcumin and an appropriate co-surfactant, such as polyoxyethylene [20] sorbitan monooleate (Tween-80). The soybean oil and HEPC were dissolved in $4 \mathrm{ml}$ of chloroform. Curcumin was dissolved in $4 \mathrm{ml}$ of chloroform. Tween- 80 was dissolved in $2 \mathrm{ml}$ of chloroform. A mixture of these 3 solutions was dried by rotary evaporation for $20 \mathrm{~min}$, and then subjected to vacuum desiccation for $3 \mathrm{~h}$ to generate a dry thin film. The film was hydrated with $30 \mathrm{ml}$ of distilled water warmed at $50^{\circ} \mathrm{C}$ in a bath-type sonicator (Branson-Yamato 2510, Bransonic; Emerson-Japan, Kanagawa, Japan). In order to obtain the desired emulsion particle size, the hydrated curcumin emulsion was sonicated for 60 min maximum with a bath-type sonicator thermostated to $25-55^{\circ} \mathrm{C}$. The sonication was performed as follows: $3 \mathrm{~min}$ of sonication and subsequent $2 \mathrm{~min}$ of cooling, which was repeated for $60 \mathrm{~min}$.

Measurement of particle size. The particle size of the lipid nanoemulsions was measured by a dynamic light scattering method using a Zetasizer 3000HSA (Malvern Instruments Ltd., Worcestershire, UK) at room temperature. Particle size data were expressed as the means of the Z-average of 3 independent batches of the nanoemulsions.

Cell culture. RAW264.7 murine macrophages were cultured in Dulbecco's modified Eagle's medium (DMEM) supplemented with $1.0 \mathrm{~g} / 1$ glucose and sodium pyruvate plus $10 \%$ fetal bovine serum (FBS), $5 \mathrm{mM}$ L-glutamine, $50 \mathrm{U} / \mathrm{ml}$ penicillin and $50 \mathrm{U} / \mathrm{ml}$ streptomycin. Rat basophilic leukemia RBL-2H3 cells were cultured in Eagle's minimum essential medium (EMEM) supplemented with 10\% FBS, $5 \mathrm{mM}$ L-glutamine, $50 \mathrm{U} / \mathrm{ml}$ penicillin and $50 \mathrm{U} / \mathrm{ml}$ streptomycin. All cells in standard medium were cultivated in a humidified incubator of $95 \%$ air and $5 \% \mathrm{CO}_{2}$ at $37^{\circ} \mathrm{C}$.

Animals. Male 8-week-old C57BL/6j mice (body weight range, 22-27 g) and male 6-week-old ICR mice (body weight range, 25-27 g) were obtained from Japan SLC, Inc. (Hamamatsu, Japan). Mice that had been bred in-house with free access to a standard diet (MF; Oriental Yeast Co., Ltd., Osaka, Japan) and water were used for all the experiments. All mice were maintained under a $12 \mathrm{~h}$ light/dark cycle and housed at a room temperature of $25^{\circ} \mathrm{C}$. All animal studies were approved by the Kobe Gakuin University Animal Committee (Kobe, Japan) according to the university guidelines for the 'Care and Use of Laboratory Animals'.

Measurement of TNF- $\alpha$ secretion in RAW264.7 cells. The RAW264.7 cells were seeded at $4 \times 10^{4}$ cells/well in a 96-well plate and incubated for $24 \mathrm{~h}$. The cells were then treated with a final concentration of $6.5 \mu \mathrm{g} / \mathrm{ml}$ of the test compound for $30 \mathrm{~min}$ prior to the addition of $50 \mathrm{ng} / \mathrm{ml}$ LPS, a major component of the outer membrane of Gram-negative bacteria. Following LPS stimulation for $24 \mathrm{~h}$, the cell culture medium was collected and the amount of secreted TNF- $\alpha$ was quantified using a commercially available enzyme-linked immunosorbent assay (ELISA) development system (eBioscience Co., Ltd., Kobe, Japan) in accordance with the manufacturer's instructions.

Measurement of serum levels of TNF- $\alpha$ in mice. The $\mathrm{C} 57 \mathrm{BL} / 6 \mathrm{j}$ mice were given only water for $24 \mathrm{~h}$ prior to the 
oral administration of the test samples. The mice were orally administered $8 \mathrm{mg} / \mathrm{kg}$ body weight of the test compound or $200 \mu \mathrm{l}$ of distilled water as a vehicle control. After $2 \mathrm{~h}$, the mice were intraperitoneally injected with $250 \mu \mathrm{g} / \mathrm{kg}$ body weight of LPS dissolved in phosphate-buffered saline (PBS) or $200 \mu \mathrm{l}$ of PBS as a vehicle control. After $1 \mathrm{~h}$, the mice were sacrificed, and whole blood was collected. The serum was separated by centrifugation at $5,000 \mathrm{xg}$ for $10 \mathrm{~min}$ at $4^{\circ} \mathrm{C}$. The serum TNF- $\alpha$ levels were measured using the above-mentioned ELISA kit.

Measurement of $\beta$-hexosaminidase release in $\mathrm{RBL}-2 \mathrm{H} 3$ cells. It has been previously reported that the release of $\beta$-hexosaminidase positively correlates with the release of histamine, which is a major component of mast cell granules (34); therefore, in this study, mast cell degranulation was estimated using a $\beta$-hexosaminidase release assay as previously described by Sato et al (35), with minor modifications. Briefly, the RBL-2H3 cells were seeded at $2 \times 10^{5}$ cells/well in a 24-well plate and incubated for $24 \mathrm{~h}$. The cells were washed with Tyrode's buffer $(8 \mathrm{mg} / \mathrm{ml} \mathrm{NaCl}, 1 \mathrm{mg} / \mathrm{ml}$ glucose, $1 \mathrm{mg} / \mathrm{ml}$ $\mathrm{NaHCO}_{3}, 0.2 \mathrm{mg} / \mathrm{ml} \mathrm{KCl}$ and $0.05 \mathrm{mg} / \mathrm{ml} \mathrm{NaH}_{2} \mathrm{PO}_{4}$ ) containing

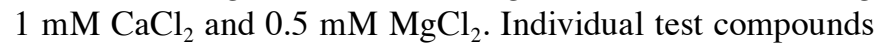
were added at a final concentration of $6.5 \mu \mathrm{g} / \mathrm{ml}$ in Tyrode's buffer. The cells were then stimulated with $5 \mu \mathrm{M}$ of A23187 (a calcium ionophore) and incubated for $90 \mathrm{~min}$. Following centrifugation for $3 \mathrm{~min}$ at $10^{\circ} \mathrm{C}, 100 \mu \mathrm{l}$ of the cell supernatant were mixed with substrate solution $(2 \mathrm{mM} p$-nitrophenyl- $N$ acetyl- $\beta$-D-glucosaminide in $0.1 \mathrm{M}$ sodium citrate buffer, $\mathrm{pH} 4.5$ ). The mixture was incubated for $90 \mathrm{~min}$ at $37^{\circ} \mathrm{C}$ and the reaction was then terminated by the addition of stop buffer composed of $0.2 \mathrm{M}$ glycine buffer at $\mathrm{pH}$ 11.0. The absorbance at $405 \mathrm{~nm}$ was measured using a microplate reader (Vmax-K; Molecular Devices, LLC, Sunnyvale, CA, USA). The effects of the test compounds on the release of $\beta$-hexosaminidase are expressed as a percentage, calculated using the following formula: percentage activity $=[(\beta$-hexosaminidase release with test compound $/ \beta$-hexosaminidase release without test compound] $x 100$.

Measurement of anti-anaphylactic activity in mice. The passive cutaneous anaphylaxis (PCA) reaction was conducted as described in a previous study (35). The ICR mice were fasted $24 \mathrm{~h}$ prior to the experiment. The mice were sensitized by an intradermal injection of $0.1 \mu \mathrm{g}$ of anti-dinitrophenyl (DNP) immunoglobulin $\mathrm{E}$ ( $\mathrm{IgE}$ ) in the ear under chloral hydrate anesthesia, and $3 \mathrm{~h}$ later, a test compound $(100 \mathrm{mg} / \mathrm{kg})$ or saline were orally administered. The mice were then challenged by an intravenous administration of $0.2 \mathrm{ml}(1 \mathrm{mg} / \mathrm{ml})$ of DNP-labeled human serum albumin containing $2 \%$ Evans blue dye. The animals in the control group were administered saline. Thirty minutes after the challenge, the mice were subsequently sacrificed by diethyl ether anesthesia and the ears were removed and weighed. These resulting solutions were incubated in $200 \mu \mathrm{l}$ of $1 \mathrm{~N} \mathrm{KOH}$ overnight at $64^{\circ} \mathrm{C}$ for the measurement of the amount of Evans blue dye present in the exudates. The dissolved tissue solution was added to $400 \mu \mathrm{l}$ of a mixture of acetone and $0.6 \mathrm{~N}$ phosphoric acid (5/13, v/v), and the optical density of the resulting solution was measured at $620 \mathrm{~nm}$. The amount of dye in the exudates was calculated from an Evans blue standard curve and the results are expressed as the percentage of the mean exudate dye amount from the mice treated with the test compound compared to the controls.

Measurement of curcumin concentration in serum following the oral administration of the test compounds in mice. The $\mathrm{C} 57 \mathrm{BL} / 6 \mathrm{j}$ mice were given only water for $24 \mathrm{~h}$ prior to the oral administration of the test compounds. The mice were orally administered $8 \mathrm{mg} / \mathrm{kg}$ body weight of the test compound or $200 \mu \mathrm{l}$ of distilled water as a vehicle control. Blood was collected every $1 \mathrm{~h}$ from the tail vein until $5 \mathrm{~h}$ after the oral administration. Serum was separated by centrifugation at 5,000 $\mathrm{x} g$ for $10 \mathrm{~min}$ at $4^{\circ} \mathrm{C}$. Subsequently, one volume of acetonitrile was added to each volume of serum for deproteinization, and the mixture was centrifuged at 15,000 x g for $15 \mathrm{~min}$. Following centrifugation, the acetonitrile phase was collected and passed through a $0.22 \mu \mathrm{m}$ Millipore membrane filter (Millipore, Bedford, MA, USA) prior to analysis by high-performance liquid chromatography (HPLC).

The HPLC system comprised of a chromatographic pump (LC-20AD), a fluorescence detector (RF-10AXL) and a degasser (DGU-20A3) (all from Shimadzu Co., Ltd., Kyoto, Japan). A mobile phase consisting of acetonitrile and $20 \mathrm{mM}$ formic acid (45:55, v/v) was used at a flow rate of $2 \mathrm{ml} / \mathrm{min}$. A reversed-phase Mayysil RP-18GP column (4.6x150 mm, particle size $5 \mu \mathrm{m}$; Kanto Chemical Co., Inc., Tokyo, Japan) was used for the HPLC separation. The mobile phase was degassed using a bath-type sonicator (Branson-Yamato 2510, Bransonic; Emerson-Japan) before use. The HPLC running time was $10 \mathrm{~min}$ and fluorescence was detected at Ex $400 \mathrm{~nm} / \mathrm{Em} 527 \mathrm{~nm}$. The amount of curcumin in serum was calculated from the standard curve of fluorescence absorption by curcumin and the results were expressed as a percentage of the mean curcumin amount from the mice treated with the test compound compared with the controls.

Statistical analysis. All data are expressed as the means \pm standard deviation (SD) of at least 6 independent determinations for each experiment. The statistical significance between each experimental group was analyzed using the Steel-Dwass test, and a probability value of 0.01 and 0.05 was used as the criterion of significance.

\section{Results}

Formulation of curcumin lipid nanoemulsions. The 5 formulations of curcumin lipid nanoemulsion are listed in Table I. A curcumin loading dose of $15 \mathrm{mg}$ was used. In this experiment, soybean oil was used as the oil component of the curcumin lipid nanoemulsions, since curcumin is a lipophilic molecule that exhibits limited solubility in water. A schematic illustrates the possible structure of the curcumin lipid nanoemulsion (Fig. 1). HEPC and a co-surfactant, such as Tween-80, surround the soybean oil in which curcumin is dissolved.

The preparation conditions were optimized according to the sonication time and the temperature of the water bath. Curcumin lipid nanoemulsions with particle sizes of 50, 100 and $200 \mathrm{~nm}$ were successfully prepared. The particle size distribution of these nanoemulsions appeared as a single peak except for the 200-nm sample (Fig. 2A). We also prepared a 50-nm blank emulsion without curcumin and a water 
Table I. Formulation of the curcumin lipid nanoemulsions.

Formulation

Components and conditions

\begin{tabular}{ccc}
\hline $\begin{array}{c}50-\mathrm{nm} \text { Blank } \\
\text { emulsion }\end{array}$ & $\begin{array}{c}50 \text {-nm Curcumin } \\
\text { emulsion }\end{array}$ & $\begin{array}{c}100 \text { nm-Curcumin } \\
\text { emulsion }\end{array}$
\end{tabular}

50-nm Blank
emulsion emulsion

\begin{tabular}{|c|c|c|c|c|c|}
\hline Soybean oil (ml) & 1 & 1 & 1 & 1 & - \\
\hline Curcumin (mg) & - & 15 & 15 & 15 & 15 \\
\hline HEPC (mg) & 250 & 250 & 250 & 250 & - \\
\hline Tween-80 (mg) & 350 & 350 & 350 & 360 & - \\
\hline Distilled water $(\mathrm{ml})$ & 30 & 30 & 30 & 30 & 30 \\
\hline Total sonication time (min) & 60 & 60 & 5 & 3 & 60 \\
\hline Temperature of water bath $\left({ }^{\circ} \mathrm{C}\right)$ & 33 & 33 & 25 & 30 & 33 \\
\hline
\end{tabular}

\begin{tabular}{|c|c|c|c|c|c|}
\hline Soybean oil (ml) & 1 & 1 & 1 & 1 & - \\
\hline Curcumin (mg) & - & 15 & 15 & 15 & 15 \\
\hline HEPC (mg) & 250 & 250 & 250 & 250 & - \\
\hline Tween-80 (mg) & 350 & 350 & 350 & 360 & - \\
\hline Distilled water $(\mathrm{ml})$ & 30 & 30 & 30 & 30 & 30 \\
\hline Total sonication time (min) & 60 & 60 & 5 & 3 & 60 \\
\hline Temperature of water bath $\left({ }^{\circ} \mathrm{C}\right)$ & 33 & 33 & 25 & 30 & 33 \\
\hline
\end{tabular}

200 nm-Curcumin emulsion
Curcumin suspension

HEPC, hydrogenated L- $\alpha$-phosphatidylcholine; -, indicates zero.

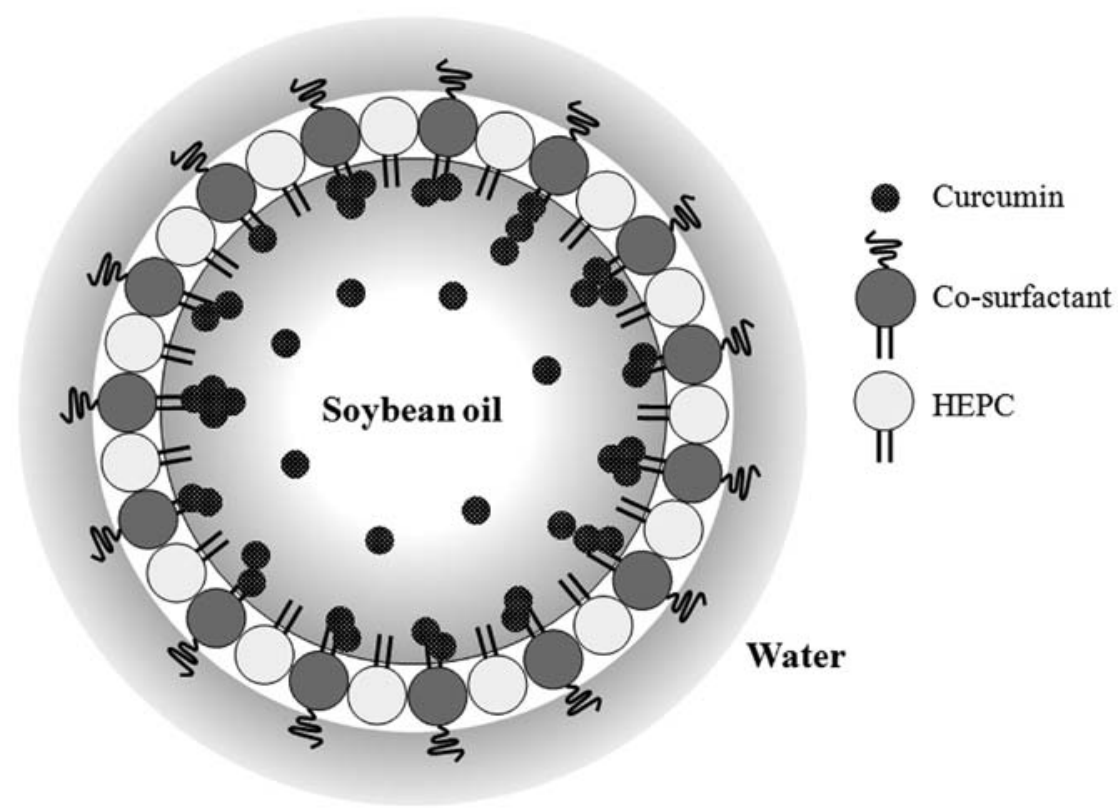

Figure 1. Schematic representation of the particle structure of a curcumin lipid nanoemulsion. The lipid nanoemulsion was an oil-in-water (O/W) emulsion consisting of soybean oil, in which curcumin was dissolved, with a particle diameter of 50-200 $\mathrm{nm}$.

suspended curcumin sample by sonication for $60 \mathrm{~min}$ at $33^{\circ} \mathrm{C}$ (i.e., curcumin suspension) as controls. The particle diameter of the curcumin suspension could not be measured, as the particle size of the curcumin in this suspension was too large. The nanoemulsions were homogeneous, optically opaque systems during storage at $4^{\circ} \mathrm{C}$ for over one month, whereas the curcumin suspension consisted of a yellow turbid layer on the top, and was unstable in dispersion (Fig. 2B).

Inhibitory effect of curcumin lipid nanoemulsions on LPS-induced TNF- $\alpha$ secretion in vitro. LPS-stimulated basophils produce and release cytokines, eventually recruiting inflammatory cells with neutrophils and eosinophils $(36,37)$. The inflammatory cytokine, TNF- $\alpha$, activates the nuclear factor $-\kappa B(N F-\kappa B)$ signaling pathway by binding to the $\mathrm{TNF}-\alpha$ receptor, thereby initiating an inflammatory response implicated in various inflammatory diseases (38). The inhibitory effects of the various particle sizes of the curcumin lipid nanoemulsions against LPS-induced TNF- $\alpha$ secretion in RAW264.7 cells were examined and the anti-inflammatory effects of the formulations were determined. In the RAW264.7 cells, none of the prepared curcumin lipid nanoemulsions tested showed cytotoxicity at $10 \mu \mathrm{g} / \mathrm{ml}$ (data not shown); these nanoemulsions and the curcumin suspension had no effect on the proliferation of peritoneal macrophages. The RAW264.7 cells treated with $6.5 \mu \mathrm{g} / \mathrm{ml}$ of blank emulsion produced $693 \mathrm{pg} / \mathrm{ml}$ of TNF- $\alpha$ following stimulation with $50 \mathrm{ng} / \mathrm{ml}$ of LPS, and the TNF- $\alpha$ secretion in the controls was set at $100 \%$. As shown in Fig. 3A, we found that $6.5 \mu \mathrm{g} / \mathrm{ml}$ of the $100-\mathrm{nm}$ curcumin lipid nanoemulsion significantly suppressed the LPS-induced production of TNF- $\alpha$, and the suppressive effects of the formulations were ranked as follows: 100-nm curcumin 

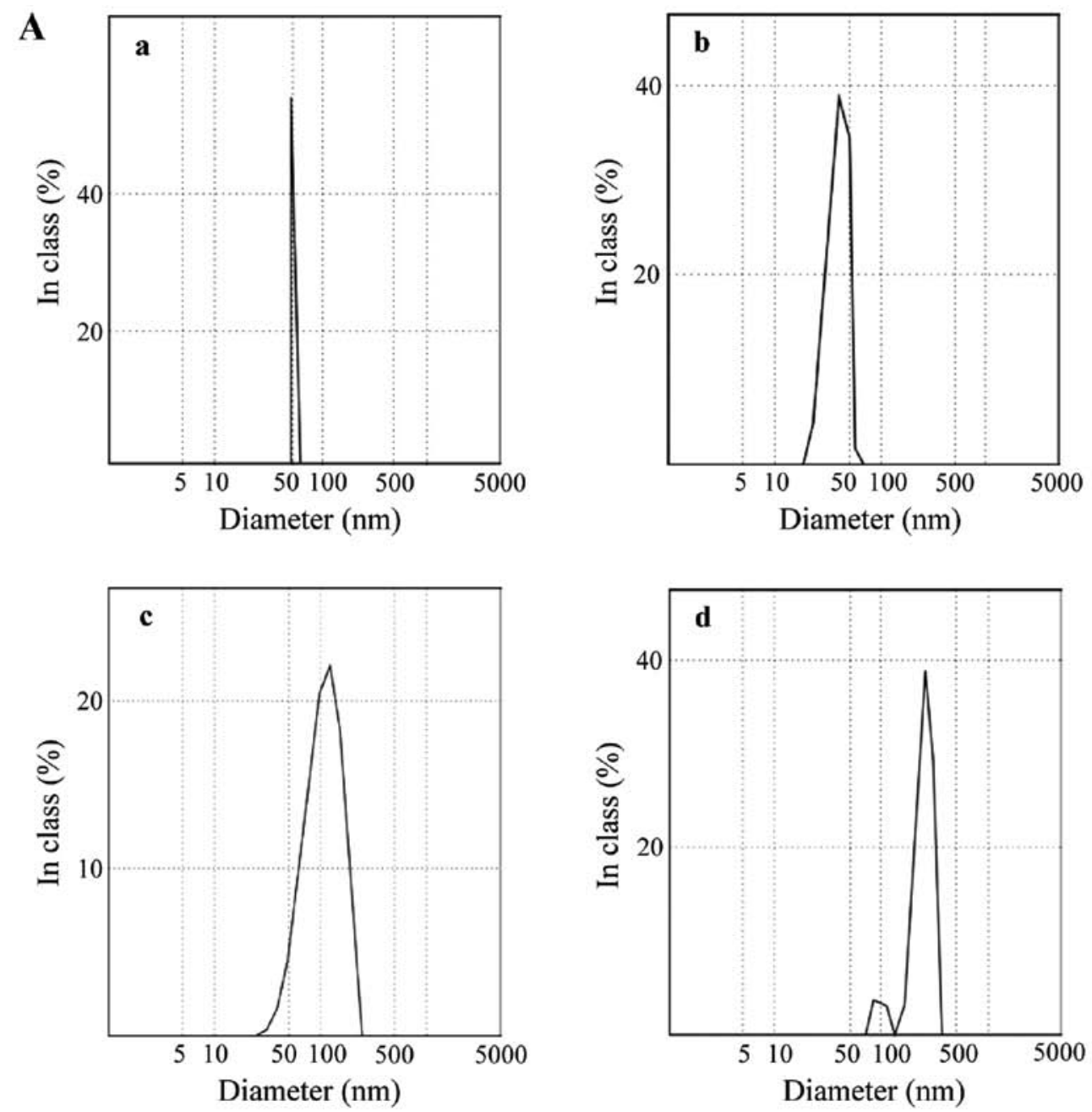

B

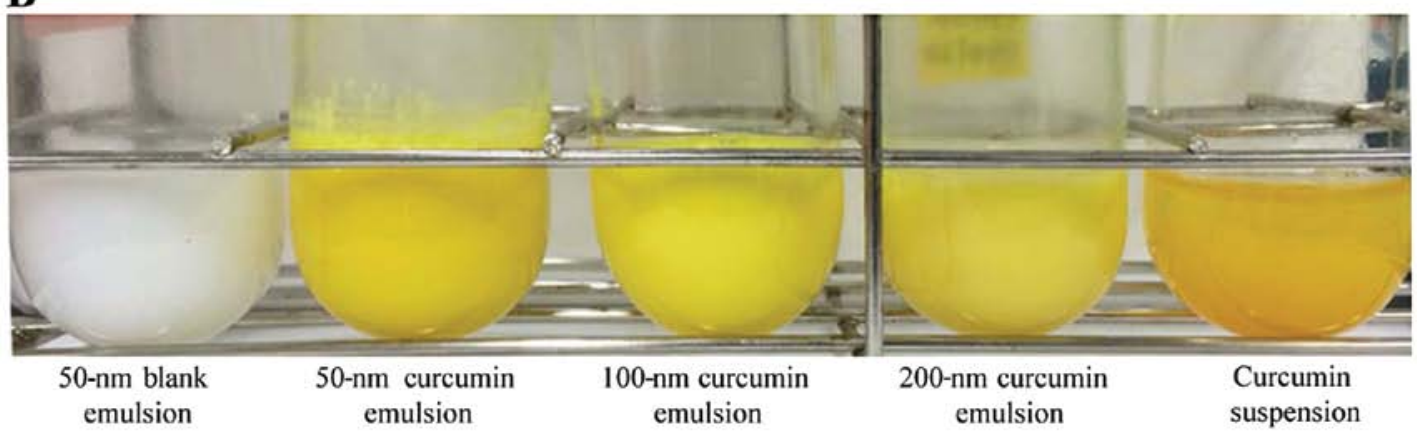

Figure 2. Preparation of curcumin lipid nanoemulsions and curcumin suspension. (A) Particle size distributions of curcumin lipid nanoemulsions in formulations. (a) 50-nm blank emulsion, (b) 50-nm curcumin emulsion, (c) 100-nm curcumin emulsion, and (d) 200-nm curcumin emulsion. (B) Scattering stability of curcumin lipid nanoemulsions and curcumin suspension. Samples were stored for 30 days at $4^{\circ} \mathrm{C}$ after production.

emulsion $>200$-nm curcumin emulsion $>50$-nm curcumin emulsion $\approx$ curcumin suspension. This result suggested that the particle size of the curcumin lipid nanoemulsions is important for the suppression of TNF- $\alpha$ production.

Inhibitory effects of curcumin lipid nanoemulsions on $L P S$-induced serum TNF- $\alpha$ production in vivo. To evaluate the anti-inflammatory effects of curcumin lipid nanoemulsions in vivo, we investigated their inhibitory activity against LPS-induced serum TNF- $\alpha$ production in mice. As shown in
Fig. 3B, the administration of LPS $(250 \mu \mathrm{g} / \mathrm{kg})$ significantly increased the production of TNF- $\alpha$; however, the blank emulsion at a dose of $8 \mathrm{mg} / \mathrm{kg}$ had no effect $(100 \%$ TNF- $\alpha$ production). The $100-\mathrm{nm}$ curcumin lipid nanoemulsion $(8 \mathrm{mg} /$ $\mathrm{kg}$ ) had the most prominent suppressive effect on the production of TNF- $\alpha$ among the formulations tested. The 50- and 200-nm curcumin lipid nanoemulsions slightly suppressed TNF- $\alpha$ production, whereas the curcumin suspension showed minimal effects. These in vivo results support the results of the in vitro experiment with cultured RAW264.7 cells. 
A

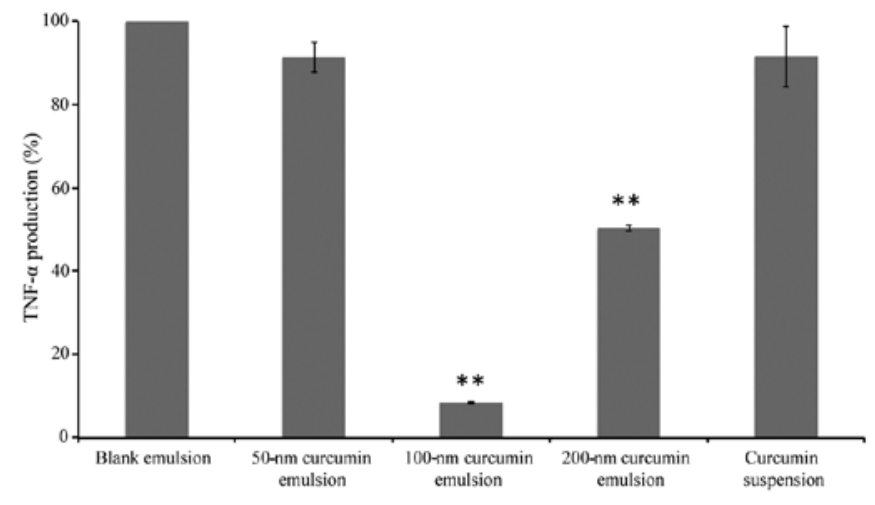

B

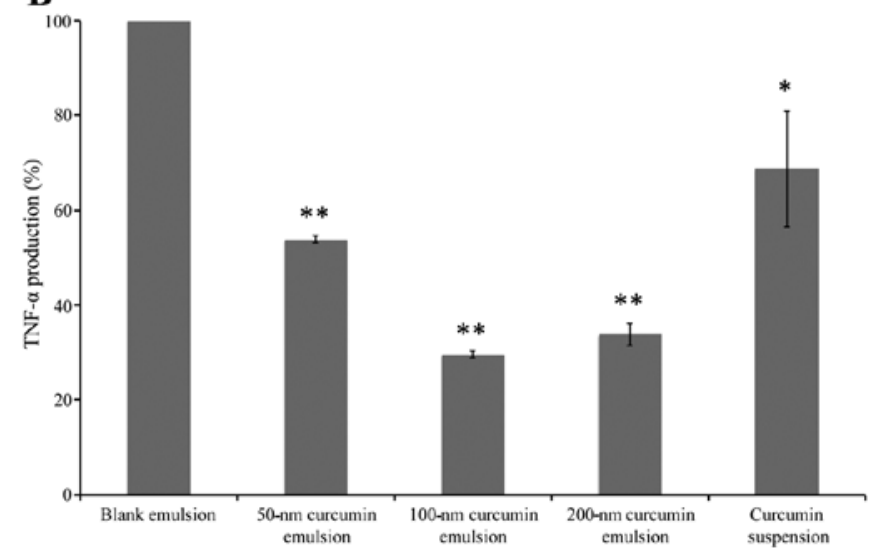

Figure 3. Anti-inflammatory activities of curcumin lipid nanoemulsions and curcumin suspension. (A) In vitro inhibitory effect of $6.5 \mu \mathrm{g} / \mathrm{ml}$ curcumin lipid nanoemulsions on the production of tumor necrosis factor- $\alpha$ (TNF- $\alpha$ ) by RAW264.7 cells stimulated with $50 \mathrm{ng} / \mathrm{ml}$ lipopolysaccharide (LPS). Data are shown as the means \pm SD of 10 independent experiments. ${ }^{* * *} \mathrm{P}<0.01$ vs. controls (blank emulsion-treated cells). (B) In vivo inhibitory effect of $8 \mathrm{mg} / \mathrm{kg}$ curcumin lipid nanoemulsions on serum $\mathrm{TNF}-\alpha$ production in mice serum administered $250 \mu \mathrm{g} / \mathrm{kg}$ LPS. Data are shown as the means \pm SD of 6 independent experiments. ${ }^{* *} \mathrm{P}<0.01$ and ${ }^{*} \mathrm{P}<0.05$ vs. controls (blank emulsion-treated mice).

Inhibitory effects of curcumin lipid nanoemulsions on the release of $\beta$-hexosaminidase in vitro. The release of $\beta$-hexosaminidase is commonly used as an indicator of mast cell degranulation (39). The release of histamine and other chemical mediators from mast cells is important in initiating the immediate type anaphylactic reaction (40). Thus, the effect of the curcumin lipid nanoemulsions on the release of $\beta$-hexosaminidase was investigated using RBL-2H3 cells treated with the calcium ionophore, A23187. The results confirmed that the nanoemulsions and the curcumin suspension did not affect RBL-2H3 cell growth and did not inhibit $\beta$-hexosaminidase enzyme activity (data not shown). The degree of degranulation was calculated from $\beta$-hexosaminidase activity in the supernatant and cell lysate. As a result, the 50-, 100- and 200-nm curcumin nanoemulsions inhibited the release of $\beta$-hexosaminidase by 35,61 and $40 \%$, respectively, at a dose of $10 \mu \mathrm{g} / \mathrm{ml}$ compared to the controls (curcumin suspension) (Fig. 4A). These results indicate the importance of particle size in the activity of curcumin lipid nanoemulsions.

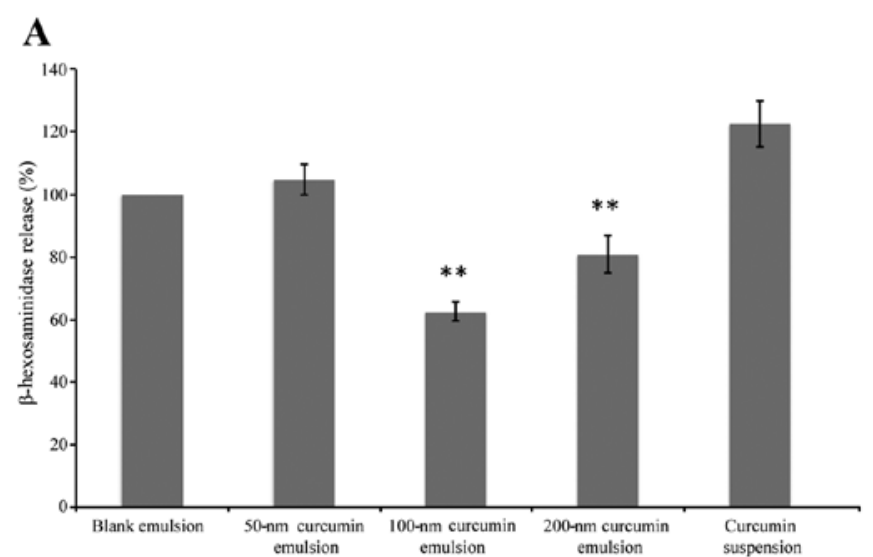

B

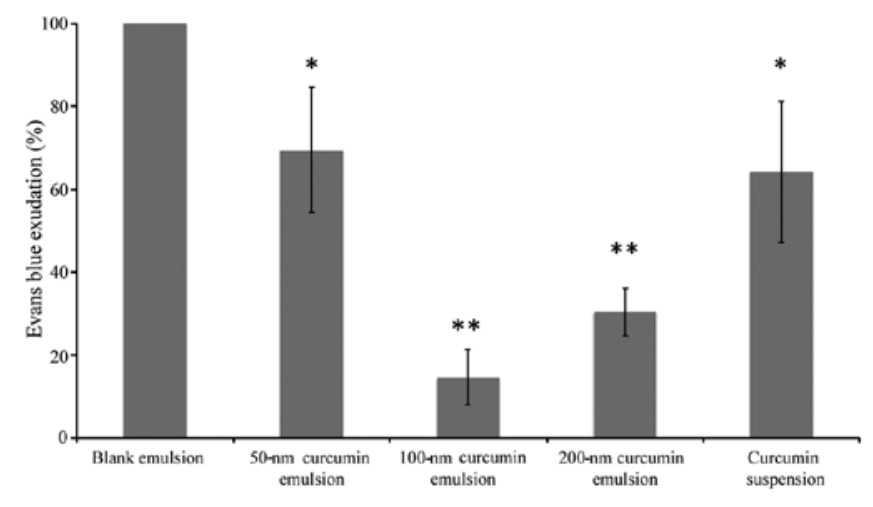

Figure 4. Anti-allergic activities of curcumin lipid nanoemulsions and curcumin suspension. (A) In vitro inhibitory effect of $10 \mu \mathrm{g} / \mathrm{ml}$ curcumin lipid nanoemulsions on the release of $\beta$-hexosaminidase in rat basophilic leukemia (RBL)-2H3 cells stimulated with $5 \mu \mathrm{M}$ A23187 (a calcium ionophore). Data are shown as the means $\pm \mathrm{SD}$ of 10 independent experiments. ${ }^{* *} \mathrm{P}<0.01$ vs. controls (blank emulsion-treated cells). (B) In vivo anti-allergic effect of $8 \mathrm{mg} / \mathrm{kg}$ curcumin lipid nanoemulsions on the immunoglobulin ( $\mathrm{IgE}$ )dependent passive cutaneous anaphylaxis (PCA) reaction in mice. Evans blue exudation shows anaphylactic activity by PCA reaction. Data are shown as the means \pm SD of 6 independent experiments. ${ }^{* *} \mathrm{P}<0.01$ and ${ }^{*} \mathrm{P}<0.05$ vs. controls (blank emulsion-treated mice).

Anti-allergic effect of curcumin lipid nanoemulsions in vivo. The IgE-mediated PCA reaction is frequently used as a tool for the in vivo investigation of the mechanisms of immediate hypersensitivity reactions (35). In this study, we examined the in vivo bioactivity of curcumin lipid nanoemulsions against allergic reactions. The curcumin nanoemulsions (50, 100 and $200 \mathrm{~nm}$ ) inhibited the PCA reaction in mice by 31,85 and $69 \%$, respectively, at a dose of $8 \mathrm{mg} / \mathrm{kg}$ (Fig. 4B). By contrast, under the same conditions, the 50-nm curcumin emulsion and the curcumin suspension had no effect on the PCA reaction. These in vivo results support the observed in vitro inhibition of $\beta$-hexosaminidase release activity. The anti-allergic activity was ranked in the following order: 100-nm curcumin emulsion $>200$-nm curcumin emulsion $>50$-nm curcumin emulsion $\approx$ curcumin suspension.

Serum absorption of curcumin lipid nanoemulsions in mice. From the above results, the 100-nm curcumin lipid nanoemulsion showed the strongest anti-inflammatory and anti-allergic 


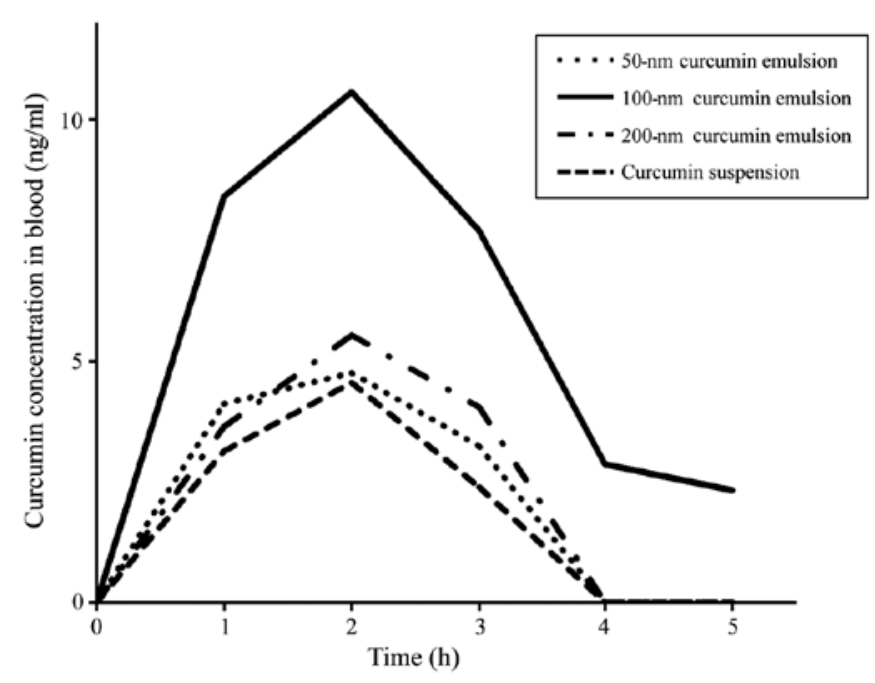

Figure 5. Serum curcumin absorption efficiency after the oral intake of curcumin lipid nanoemulsions and curcumin suspension in mice. Time course of serum curcumin levels after the oral administration of $8 \mathrm{mg} / \mathrm{kg}$ of curcuminloaded samples in mice. The amount of curcumin was measured using high-performance liquid chromatography (HPLC) with fluorescence detection.

activities in vitro and in vivo among the emulsions tested. In order to investigate in vivo serum absorption of the curcumin lipid nanoemulsions, we examined serum curcumin concentrations in mice over time. Fig. 5 shows the blood curcumin concentrations following treatment with the 50-, 100- and 200-nm curcumin emulsions. Two hours after the oral administration of the test compounds at a dose of $8 \mathrm{mg} / \mathrm{kg}$, the highest curcumin blood concentration was observed with the $100-\mathrm{nm}$ lipid nanoemulsion, followed by the 200- and 50-nm curcumin lipid nanoemulsions. These results suggest that the absorption efficiency differs according to the lipid nanoemulsion size, with the $100-n m$ particle size showing efficient serum curcumin absorption in mice.

\section{Discussion}

Curcumin is a lipophilic molecule that exists in the enol-tautomer form. It exhibits limited solubility in water, slight solubility in methanol, and good solubility in dimethyl sulfoxide (DMSO) and chloroform (41). To overcome its limited water-solubility, a number of new approaches have been investigated to deliver curcumin effectively using a lipid-based nanoparticle carrier method, such as liposome encapsulation $(42,43)$. The formulation of the curcumin lipid nanoemulsion in this study was modified from that for sulfoquinovosyl acylglycerol-containing emulsions previously demonstrated (44). The main components of those emulsions were soybean oil, distilled water, sulfoquinovosyl acylglycerol, and HEPC from egg yolk. HCO-60 was used as a co-surfactant to effectively reduce the particle size, as well as load the nanoemulsion with the target compound (i.e., sulfoquinovosyl acylglycerol). Tween-80 was also effectively used as a co-surfactant to reduce the particle size of nanoemulsions. In a previous study of ours, we demonstrated that Tween-80 produced much smaller particles in curcumin lipid emulsions compared to HCO-60 (45). Thus, Tween-80 was used as the co-surfactant in this study. Notably, Tween- 80 has been commonly used as a stabilizer in commercially available lipid emulsion preparations for some time $(46,47)$. Thus, it is an attractive co-surfactant for curcumin nanoemulsions as it produces a curcumin emulsion with a particle size that is sufficiently small for long-term circulation in the blood and is capable of extravasating through blood capillaries in tissues under inflammatory and/or allergic conditions.

A good emulsion was obtained in the preliminary experiments with HEPC. Hence, HEPC was selected as the emulsifier for the curcumin lipid nanoemulsions (Table I). In order to evaluate the effects of co-surfactant and the sonication time on the mean particle diameter of lipid nanoemulsions, a series of samples was prepared with Tween-80 as the co-surfactant and soybean oil as the oil component by increasing the sonication time, with $15 \mathrm{mg}$ of initial curcumin loading (Table I). The nanoemulsions were prepared at an HEPC:co-surfactant weight ratio of 1:1.4. Thus, the outer monolayer of the oil core in the lipid nanoemulsions was composed of an HEPC:Tween-80 molar ratio of 5.7:4.3, assuming that all surfactant molecules were arranged on the interface of the oil core and water.

Soybean oil was assessed for use as the oil component. It has been widely used as a model system for lipid emulsion studies, and is commonly used for commercially available fat emulsions $(48,49)$. In general, the formula of intralipid was composed of $10-30 \% \mathrm{w} / \mathrm{w}$ soybean oil. The viscosity range of soybean oil is between 69 and $10,000 \mathrm{mPa} \cdot \mathrm{s}$ at $24^{\circ} \mathrm{C}(50)$. In this study, the curcumin nanoemulsion with soybean oil showed smaller particle diameters of 50 to $200 \mathrm{~nm}$ (Fig. 2). This difference in the particle diameter may be attributed to the lower viscosity of the soybean oil, which readily allows the breakup of oil droplets during ultrasonication, generating smaller-sized nanoemulsions (32).

The relatively small size of the droplets in nanoemulsions $(<200 \mathrm{~nm})$ means that they often have different physicochemical and biological properties than conventional emulsions (>200 nm). Furthermore, nanoemulsions have been reported to have better stability against particle aggregation and gravitational separation due to their small droplet size $(26,51)$. The bioavailability of encapsulated lipophilic components within the gastrointestinal tract may be increased by using nanoemulsions due to their relatively small droplet size (52). Thus, one of the objectives of the present study was to determine the influence of droplet size on curcumin bioactivities, such as anti-inflammatory activity (Fig. 3) and anti-allergic activity (Fig. 4). The results of this study demonstrated that the 100-nm curcumin lipid nanoemulsion exhibited the highest bioactivity when orally administered to mice. These phenomena may be due to the fact that curcumin reaches a maximum blood concentration with the 100-nm lipid nanoemulsion (Fig. 5). We are currently attempting to clarify the molecular mechanisms regulating the efficient serum absorption of curcumin, delivered in a 100-nm lipid nanoemulsion. Future studies on curcumin lipid nanoemulsions are warranted in pre-clinical in vivo models of inflammation, allergies and other diseases that may benefit from the effects of curcumin.

In conclusion, in this study, we focused on the in vitro and in vivo bioactivities of curcumin, such as the anti-inflammatory and anti-allergy effects. We investigated the effects of particle diameter $(50,100$ and $200 \mathrm{~nm})$ on the bioactivities of curcumin lipid nanoemulsions, and found that the 100-nm emulsion 
had the best bioactivity both in vitro and in vivo. The oral administration of the $100-\mathrm{nm}$ nanoemulsion resulted in the highest serum curcumin absorption in mice. Curcumin lipid nanoemulsions provide an opportunity to expand the clinical repertoire of this efficacious agent by enabling its aqueous dispersion. The 100-nm curcumin nanoemulsion represents a promising tool when testing the potential bioactive effects of curcumin in clinical trials.

\section{Acknowledgements}

This study was supported in part by the Ministry of Education, Culture, Sports, Science and Technology (MEXT, Japan)Supported Program for the Strategic Research Foundation at Private Universities, 2012-2016. Y.M. acknowledges Grantsin-Aid for Scientific Research (C) (no. 24580205) from MEXT, and the 25th (2014) Cosmetology Research Foundation (Japan).

\section{References}

1. Anand P, Kunnumakkara AB, Newman RA and Aggarwal BB: Bioavailability of curcumin: Problems and promises. Mol Pharm 4: 807-818, 2007.

2. Ammon HP, Safayhi H, Mack T and Sabieraj J: Mechanism of antiinflammatory actions of curcumine and boswellic acids. J Ethnopharmacol 38: 113-119, 1993.

3. Banerjee A and Nigam SS: Antimicrobial efficacy of the essential oil of Curcuma longa. Indian J Med Res 68: 864-866, 1978.

4. Bhavani Shankar TN and Sreenivasa Murthy V: Effect of turmeric (Curcuma longa) fractions on the growth of some intestinal and pathogenic bacteria in vitro. Indian J Exp Biol 17: $1363-1366,1979$.

5. Sawada T, Yamahara J, Shimazu S and Ohta T: Evaluation of crude drugs by bioassay. III. Comparison with local variation of contents and the fungistatic action of essential oil from the root of Curcuma longa. Shoyakugaku Zasshi 25: 11-16, 1971.

6. Rao DS, Sekhara NC, Satyanarayana MN and Srinivasan M: Effect of curcumin on serum and liver cholesterol levels in the rat. J Nutr 100: 1307-1315, 1970.

7. Limtrakul P, Anuchapreeda S, Lipigorngoson S and Dunn FW: Inhibition of carcinogen induced c-Ha-ras and c-fos protooncogenes expression by dietary curcumin. BMC Cancer 1: 1-7, 2001 .

8. Anuchapreeda S, Limtrakul P, Thanarattanakorn P, Sittipreechacharn S and Chanarat P: Inhibitory effect of curcumin on WT1 gene expression in patient leukemic cells. Arch Pharm Res 29: 80-87, 2006.

9. Anuchapreeda S, Thanarattanakorn P, Sittipreechacharn S, Chanarat P and Limtrakul P: Curcumin inhibits WT1 gene expression in human leukemic K562 cells. Acta Pharmacol Sin 27: 360-366, 2006.

10. Anuchapreeda S, Tima S, Duangrat $C$ and Limtrakul P: Effect of pure curcumin, demethoxycurcumin, and bisdemethoxycurcumin on WT1 gene expression in leukemic cell lines. Cancer Chemother Pharmacol 62: 585-594, 2008.

11. Polasa K, Raghuram TC, Krishna TP and Krishnaswamy K: Effect of turmeric on urinary mutagens in smokers. Mutagenesis 7: 107-109, 1992.

12. Roy RG, Madesayaa NM, Ghosh RB, Gopalakrishnan DV, Murthy NN, Dorairaj TJ and Sitaraman NL: Study on inhalation therapy by an indigenous compound on $P$. vivax and $P$. falciparum infections - a preliminary communication. Indian J Med Res 64: 1451-1455, 1976.

13. Azuine MA and Bhide SV: Chemopreventive effect of turmeric against stomach and skin tumors induced by chemical carcinogens in Swiss mice. Nutr Cancer 17: 77-83, 1992.

14. Dorai T, Cao YC, Dorai B, Buttyan R and Katz AE: Therapeutic potential of curcumin in human prostate cancer. III. Curcumin inhibits proliferation, induces apoptosis, and inhibits angiogenesis of LNCaP prostate cancer cells in vivo. Prostate 47: 293-303, 2001.

15. Anuchapreeda S, Muangmoonchai R and Limtrakul P: Effect of curcuminoids on MDR1 gene promoter activity in human cervical carcinoma cells. Chiang Mai Med Bull 41: 189-202, 2002.
16. Mizushina Y, Hirota M, Murakami C, Ishidoh T, Kamisuki S, Shimazaki N, Takemura M, Perpelescu M, Suzuki M, Yoshida H, et al: Some anti-chronic inflammatory compounds are DNA polymerase $\lambda$-specific inhibitors. Biochem Pharmacol 66: 1935-1944, 2003

17. Takeuchi T, Ishidoh T, Iijima H, Kuriyama I, Shimazaki N, Koiwai O, Kuramochi K, Kobayashi S, Sugawara F, Sakaguchi K, et al: Structural relationship of curcumin derivatives binding to the BRCT domain of human DNA polymerase $\lambda$. Genes Cells 11: 223-235, 2006.

18. Nishida M, Nishiumi S, Mizushina Y, Fujishima Y, Yamamoto K, Masuda A, Mizuno S, Fujita T, Morita Y, Kutsumi H, et al: Monoacetylcurcumin strongly regulates inflammatory responses through inhibition of NF- $\mathrm{KB}$ activation. Int $\mathrm{J}$ Mol Med 25: 761-767, 2010.

19. Mizushina Y, Nishida M, Azuma T and Yoshida M: Inhibition of DNA polymerase $\lambda$, a DNA repair enzyme, and anti-inflammation: chemical knocked out analysis for DNA polymerase $\lambda$ using curcumin derivatives. DNA Repair and Human Health. Chapter 31. InTech. Vengrova S (ed), pp777-792, 2011.

20. Cheng AL, Hsu CH, Lin JK, Hsu MM, Ho YF, Shen TS, Ko JY, Lin JT, Lin BR, Ming-Shiang W, et al: Phase I clinical trial of curcumin, a chemopreventive agent, in patients with high-risk or pre-malignant lesions. Anticancer Res 21: 2895-2900, 2001

21. Garcea G, Berry DP, Jones DJ, Singh R, Dennison AR, Farmer PB, Sharma RA, Steward WP and Gescher AJ: Consumption of the putative chemopreventive agent curcumin by cancer patients: Assessment of curcumin levels in the colorectum and their pharmacodynamic consequences. Cancer Epidemiol Biomarkers Prev 14: 120-125, 2005.

22. Kanai M, Yoshimura K, Asada M, Imaizumi A, Suzuki C, Matsumoto S, Nishimura T, Mori Y, Masui T, Kawaguchi Y, et al: A phase I/II study of gemcitabine-based chemotherapy plus curcumin for patients with gemcitabine-resistant pancreatic cancer. Cancer Chemother Pharmacol 68: 157-164, 2011.

23. Sharma RA, Euden SA, Platton SL, Cooke DN, Shafayat A, Hewitt HR, Marczylo TH, Morgan B, Hemingway D, Plummer SM, et al: Phase I clinical trial of oral curcumin: Biomarkers of systemic activity and compliance. Clin Cancer Res 10: 6847-6854, 2004.

24. Vareed SK, Kakarala M, Ruffin MT, Crowell JA, Normolle DP, Djuric Z and Brenner DE: Pharmacokinetics of curcumin conjugate metabolites in healthy human subjects. Cancer Epidemiol Biomarkers Prev 17: 1411-1417, 2008.

25. Porter CJ, Trevaskis NL and Charman WN: Lipids and lipidbased formulations: Optimizing the oral delivery of lipophilic drugs. Nat Rev Drug Discov 6: 231-248, 2007.

26. Solans C, Izquierdo P, Nolla J, Azemar N and Garcia-Celma MJ: Nanoemulsions. Curr Opin Colloid Interface Sci 10: 102-110, 2005.

27. Wheeler JJ, Wong KF, Ansell SM, Masin D and Bally MB: Polyethylene glycol modified phospholipids stabilize emulsions prepared from triacylglycerol. J Pharm Sci 83: 1558-1564, 1994.

28. Liu F and Liu D: Long-circulating emulsions (oil-in-water) as carriers for lipophilic drugs. Pharm Res 12: 1060-1064, 1995.

29. Kurihara A, Shibayama Y, Mizota A, Yasuno A, Ikeda M, Sasagawa K, Kobayashi T and Hisaoka M: Lipid emulsions of palmitoylrhizoxin: Effects of composition on lipolysis and biodistribution. Biopharm Drug Dispos 17: 331-342, 1996.

30. Wang Y, Mesfin GM, Rodríguez CA, Slatter JG, Schuette MR, Cory AL and Higgins MJ: Venous irritation, pharmacokinetics, and tissue distribution of tirilazad in rats following intravenous administration of a novel supersaturated submicron lipid emulsion. Pharm Res 16: 930-938, 1999.

31. Maranhão RC, Garicochea B, Silva EL, Dorlhiac-Llacer P Cadena SM, Coelho IJ, Meneghetti JC, Pileggi FJ and Chamone DA: Plasma kinetics and biodistribution of a lipid emulsion resembling low-density lipoprotein in patients with acute leukemia. Cancer Res 54: 4660-4666, 1994.

32. Miyamoto M, Hirano K, Ichikawa H, Fukumori Y, Akine Y and Tokuuye K: Preparation of gadolinium-containing emulsions stabilized with phosphatidylcholine-surfactant mixtures for neutron-capture therapy. Chem Pharm Bull (Tokyo) 47: 203-208, 1999.

33. Miyamoto M, Hirano K, Ichikawa H, Fukumori Y, Akine Y and Tokuuye K: Biodistribution of gadolinium incorporated in lipid emulsions intraperitoneally administered for neutron-capture therapy with tumor-bearing hamsters. Biol Pharm Bull 22: 1331-1340, 1999 . 
34. Razin E, Mencia-Huerta JM, Stevens RL, Lewis RA, Liu FT, Corey E and Austen KF: IgE-mediated release of leukotriene C4, chondroitin sulfate $\mathrm{E}$ proteoglycan, $\beta$-hexosaminidase, and histamine from cultured bone marrow-derived mouse mast cells. J Exp Med 157: 189-201, 1983.

35. Sato H, Kobayashi Y, Hattori A, Suzuki T, Shigekawa M and Jippo T: Inhibitory effects of water-soluble low-molecular-weight $\beta-(1,3-1,6)$ D-glucan isolated from Aureobasidium pullulans $1 \mathrm{~A} 1$ strain black yeast on mast cell degranulation and passive cutaneous anaphylaxis. Biosci Biotechnol Biochem 76: 84-88, 2012.

36. Soler-Rodriguez AM, Zhang H, Lichenstein HS, Qureshi N Niesel DW, Crowe SE, Peterson JW and Klimpel GR: Neutrophil activation by bacterial lipoprotein versus lipopolysaccharide: differential requirements for serum and CD14. J Immunol 164: 2674-2683, 2000.

37. Suzuki T, Hashimoto S, Toyoda N, Nagai S, Yamazaki N, Dong HY, Sakai J, Yamashita T, Nukiwa T and Matsushima K: Comprehensive gene expression profile of LPS-stimulated human monocytes by SAGE. Blood 96: 2584-2591, 2000.

38. Aggarwal BB: Signalling pathways of the TNF superfamily: A double-edged sword. Nat Rev Immunol 3: 745-756, 2003.

39. Supajatura V, Ushio H, Nakao A, Akira S, Okumura K, Chisei R and Ogawa H: Differential responses of mast cell Toll-like receptors 2 and 4 in allergy and innate immunity. J Clin Invest 109: $1351-1359,2002$.

40. Metcalfe DD, Peavy RD and Gilfillan AM: Mechanisms of mast cell signaling in anaphylaxis. J Allergy Clin Immunol, 124: 639-646, 2009

41. Payton F, Sandusky P and Alworth WL: NMR study of the solution structure of curcumin. J Nat Prod 70: 143-146, 2007.

42. Li L, Braiteh FS and Kurzrock R: Liposome-encapsulated curcumin: In vitro and in vivo effects on proliferation, apoptosis, signaling, and angiogenesis. Cancer 104: 1322-1331, 2005.

43. Maiti K, Mukherjee K, Gantait A, Saha BP and Mukherjee PK: Curcumin-phospholipid complex: Preparation, therapeutic evaluation and pharmacokinetic study in rats. Int J Pharm 330: 155-163, 2007.
44. Mizushina Y, Maeda N, Kawasaki M, Ichikawa H, Murakami C, Takemura M, Xu X, Sugawara F, Fukumori Y, Yoshida H, et al: Inhibitory action of emulsified sulfoquinovosyl acylglycerol on mammalian DNA polymerases. Lipids 38: 1065-1074, 2003.

45. Anuchapreeda S, Fukumori Y, Okonogi S and Ichikawa H: Preparation of lipid nanoemulsions incorporating curcumin for cancer therapy. J Nanotechnol Article 2012: 270383, 2012.

46. Hung CF, Hwang TL, Chang CC and Fang JY: Physicochemical characterization and gene transfection efficiency of lipid emulsions with various co-emulsifiers. Int J Pharm 289: 197-208, 2005.

47. Chinsriwongkul A, Opanasopit P, Ngawhirunpat T, Chareansriwilaiwat N, Sila-On W and Ruktanonchai U: Physicochemical properties of lipid emulsions formulated with high-load all-trans-retinoic acid. PDA J Pharm Sci Technol 61: 461-471, 2007.

48. Texier I, Goutayer M, Da Silva A, Guyon L and Djaker N: Cyanine-loaded lipid nanoparticles for improved in vivo fluorescence imaging. J Biomed Opt 14: 054005, 2009.

49. Goutayer M, Dufort S, Josserand V, Royere A, Heinrich E, Vinet F, Bibette J, Coll JL and Texier I: Tumor targeting of functionalized lipid nanoparticles: assessment by in vivo fluorescence imaging. Eur J Pharm Biopharm 75: 137-147, 2010.

50. Hurstand WJ and Martin RA Jr: The analysis of phospholipids in soy lecithin by HPLC. J Am Oil Chem Soc 61: 1462-1463, 1984.

51. Sonneville-Aubrun O, Simonnet JT and L'Alloret F: Nanoemulsions: A new vehicle for skincare products. Adv Colloid Interface Sci 108-109: 145-149, 2004.

52. Patel D and Sawant KK: Oral bioavailability enhancement of acyclovir by self-microemulsifying drug delivery systems (SMEDDS). Drug Dev Ind Pharm 33: 1318-1326, 2007. 